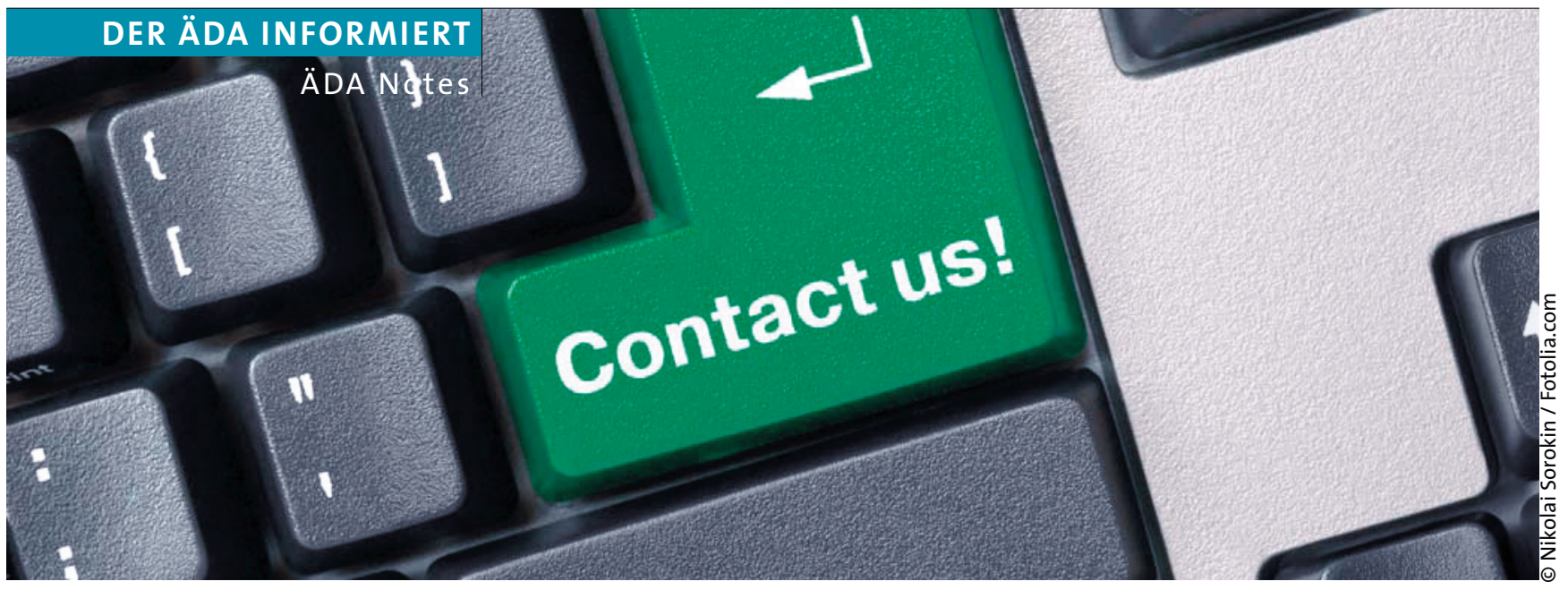

\title{
ÄDA online: Kontaktaufnahme erwünscht
}

Die direkte und zeitnahe Kommunikation mit den Mitgliedern ist dem Vorstand des ÄDA ein besonderes Anliegen. Hierfür stellt die Internetseite www.aeda.de eine vorzügliche Plattform dar besonders in Zeiten kaum mehr überschaubarer Entwicklungen im Gesundheitswesen.

m Herbst des vergangenen Jahres wurde die Homepage des Ärzteverbandes Deutscher Allergologen (ÄDA) optisch modernisiert und inhaltlich aktualisiert. Ein Besuch unter www.aeda.de lohnt also jetzt mehr denn je.

\section{Neuer passwortgeschützter Mitgliederbereich}

Die inhaltlich wichtigste Neuerung war die Einrichtung eines passwortgeschützten Bereichs, der allein den Mitgliedern des $\ddot{\mathrm{ADA}}$ vorbehalten ist. In diesem Forum finden sich zunächst die Protokolle der Mitgliederversammlungen und andere Interna des Verbandes. Es ist aber auch möglich, andere Mitglieder

Impressum „Der ÄDA informiert“

Verantwortlich für den Inhalt

Prof. Dr. Ludger Klimek, Wiesbaden

\section{Redaktion}

Markus Seidl

Verlag

(c) Urban \& Vogel GmbH, München

\section{ÄDA-Geschäftsstelle}

Carin Fresle und Ursula Raab

Service Systems, Dreieich

Tel.: (о 6103 ) 62273

Fax: (o 6103$) 697019$

E-Mail:info@aeda.de

Internet: www.aeda.de direkt zu kontaktieren. Diese sind mithilfe einer neuen Suchfunktion nach den Parametern Adresse, Telefonnummer, Telefaxnummer und - soweit vorhanden - auch E-Mail-Adresse und Website recherchierbar. Der ÄDA bietet damit eine neue vertrauliche Plattform für den fachlichen Austausch mit Kolleginnen und Kollegen. Machen Sie von dieser Möglichkeit regen Gebrauch!

\section{Bitte um E-Mail-Adresse}

Wir bitten Sie im Namen des neuen Vorstandes sehr herzlich, uns Ihre E-mailAdresse zuzusenden, um möglichst zeitnah und kostengünstig mit Ihnen in Kontakt treten zu können. Zurzeit ist nicht einmal ein Drittel der Mitglieder auf diesem Weg erreichbar, was die Kommunikation unnötig erschwert. Sie sollten von dieser Möglichkeit unbedingt Gebrauch machen, damit Sie zukünftig sowohl über das Allergo Journal als auch per E-Mail mit aktuellen Nachrichten versorgt werden.

Wir wollen mit Ihnen in Kontakt kommen. Bitte mailen Sie uns Ihre Gedanken zur Verbandsarbeit oder auch zur neuen Homepage. Machen Sie Verbesserungsvorschläge. Gestalten Sie den ÄDA, Ihren Verband, aktiv mit.

Prof. Dr. Thomas Fuchs, Göttingen Prof. Dr. Ludger Klimek, Wiesbaden

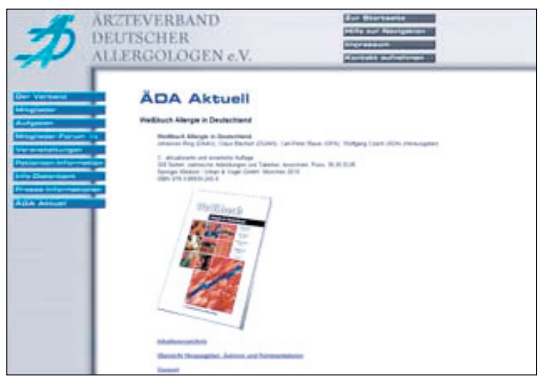

Die ÄDA-Homepage in neuem Glanz: Es sind Rubriken hinzugekommen, das Design wurde modernisiert, der grundlegende bewährte Aufbau blieb aber erhalten.

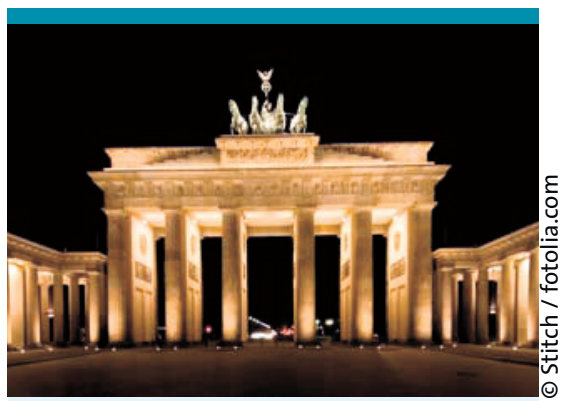

Berliner Protokoll online

Die letzte Mitgliederversammlung des ÄDÄ fand am 4. September 2009 in Berlin im Rahmen des 4. Gemeinsamen Deutschen Allergiekongresses statt. Wer nicht dabei sein konnte, kann den Sitzungsverlauf jetzt im Internet nachlesen: Das Protokoll ist nämlich seit Januar unter www.aeda.de im passwortgeschützten Mitgliederbereich der ÄDA-Homepage einsehbar. Die nächste Mitgliederversammlung wird im Rahmen des 5. Deutschen Allergiekongresses im September 2010 in Hannover stattfinden. red 